\title{
Raman Studies of the Monoiodide Complex of Mercury(II) in Dimethylsulfoxide and Pyridine Solution
}

\author{
INGMAR PERSSON $^{\mathrm{a}}$ and MAGNUS SANDSTRÖM ${ }^{\mathrm{b}}$ \\ ${ }^{a}$ Inorganic Chemistry 1, Chemical Center, University of Lund, P.O. Box 124, S-221 00 \\ Lund, Sweden and ${ }^{\mathrm{b}}$ Department of Inorganic Chemistry, The Royal Institute of \\ Technology, S-100 44 Stockholm, Sweden
}

Mercury(II) forms four mononuclear complexes, $\operatorname{HgX}_{\mathrm{j}}^{2-\mathrm{j}}, \mathrm{j}=1-4$, with chloride, bromide and iodide in the aprotic solvents dimethyl sulfoxide (DMSO) and pyridine. ${ }^{1,2}$ Thermodynamic equilibrium studies have shown that each consecutive complex $\mathrm{HgX}_{\mathrm{j}}^{2-\mathrm{j}}$ predominates in solution over a wide range of $\left[\mathrm{X}^{-}\right]$, characterized by a practically constant ligand number $\overline{\mathrm{n}}=\mathrm{j}$. In DMSO solutions, however, Raman and X-ray scattering studies ${ }^{3-5}$ have shown that the relative stability of the $\mathrm{HgX}^{+}$species is reduced when the concentration reaches about $50 \mathrm{mM}$. The $\mathrm{HgCl}^{+}$and $\mathrm{HgBr}^{+}$complexes disproportionate according to the simple mononuclear reaction

$$
2 \mathrm{HgX}^{+} \rightleftarrows \mathrm{Hg}^{2+}+\mathrm{HgX}_{2}
$$

while in $\mathrm{HgI}^{+}$solutions a dimerization occurs

$$
3 \mathrm{HgI}^{+} \rightleftarrows \mathrm{Hg}_{2} \mathrm{I}^{3+}+\mathrm{HgI}_{2}
$$

In pyridine, on the other hand, the solubilities of $\mathrm{HgXClO}_{4} \cdot \mathrm{n}$ py(s) compounds are only around $25 \mathrm{mM}$ and no evidence of disproportionation reactions has been found.

The structures of the $\mathrm{HgX}^{+}$species in dilute DMSO and pyridine solution have been studied by means of EXAFS. ${ }^{5}$ The $\mathrm{HgX}^{+}$complexes have the same coordination number and probably also a similar coordination geometry as the corresponding $\mathrm{HgX}_{2}$ complexes in DMSO and pyridine solution. ${ }^{5,6} \mathrm{The} \mathrm{HgX}^{+}$species seem to be strongly distorted tetrahedra with short bond lengths to the halide and one solvent molecule, the $\mathrm{X}-\mathrm{Hg}$-solvent unit being almost linear. The two remaining solvent molecules are weakly coordinated to mercury. The $\mathrm{Hg}-\mathrm{X}$ bond distances in $\mathrm{HgX}^{+}$are only slightly shorter, around $0.02 \AA$, than in the corresponding solvated $\mathrm{HgX}_{2}$ complexes.

In the $\mathrm{Hg}_{2} \mathrm{I}^{3+}$ complex in DMSO, a single iodine bridge forms a symmetrical $\mathrm{Hg}-\mathrm{I}-\mathrm{Hg}$ entity with an angle slightly below 90 degrees. Each mercury atom in the complex is solvated by three DMSO molecules and the $\mathrm{Hg}-\mathrm{I}$ distances are very close to that in $\mathrm{HgI}^{+}$.

The vibration frequency of $\mathrm{HgX}^{+}$in aqueous solution have been reported to be 191, 234, $338 \mathrm{~cm}^{-1}$ for iodide, bromide and chloride, respectively. ${ }^{8}$ The concentration of $\mathrm{HgX}^{+}$in the aqueous solutions studied was in all cases over $0.2 \mathrm{M}$. In aqueous solutions containing $0.2 \mathrm{M}$ iodide but with high mercury(II) concentration, $C_{\mathrm{Hg}} \geq 2 \mathrm{M}$, the complex $\mathrm{Hg}_{2} \mathrm{I}^{3+}$ was proposed to occur ${ }^{8}$ with a Raman-active vibrational frequency at $168 \mathrm{~cm}^{-1}$.

Preparations. A saturated $(1.27 \mathrm{M})$ stock solution of $\mathrm{HgIClO}_{4}$ was prepared by dissolving equimolar amounts of $\mathrm{Hg}\left(\mathrm{ClO}_{4}\right)_{2} \cdot 4 \mathrm{DMSO}$ and $\mathrm{HgI}_{2}$ in DMSO. The preparation of $\mathrm{Hg}\left(\mathrm{ClO}_{4}\right)_{2} \cdot 4 \mathrm{DMSO}$ has been reported previously. ${ }^{9}$

The pyridine solution was prepared by cooling a warm saturated solution of equimolar amounts of $\mathrm{Hg}(\mathrm{py})_{2}\left(\mathrm{ClO}_{4}\right)_{2}$ and $\mathrm{HgI}_{2}$ and filtering off the precipitate $\mathrm{HgIClO}_{4} \cdot 2.5 \mathrm{py}(\mathrm{s})$. The resulting saturated $\mathrm{HgIClO}_{4}$ solution was about $25 \mathrm{mM}$. The preparation of $\mathrm{Hg}(\mathrm{py})_{2}\left(\mathrm{ClO}_{4}\right)_{2}$ is described elsewhere. ${ }^{2}$

Measurements. Raman spectra were recorded using d.c. amplification from a D.I.L.O.R. RTI 30 triple monochromator with $4 \mathrm{~cm}^{-1}$ spectral bandwidth. The light source was the $514.5 \mathrm{~nm}$ line (approximately $500 \mathrm{~mW}$ at the sample) of a Coherent Radiation Laboratories Innova 90-5 Ar-ion laser.

Results and Discussion. Raman spectra of four $\mathrm{HgIClO}_{4}$ solutions at concentrations ranging from 0.008 to $1.27 \mathrm{M}$ in DMSO are shown in Fig. 1. Two prominent peaks, at 145

$0302-4377 / 85 \$ 2.50$

(C) 1985 Acta Chemica Scandinavica 

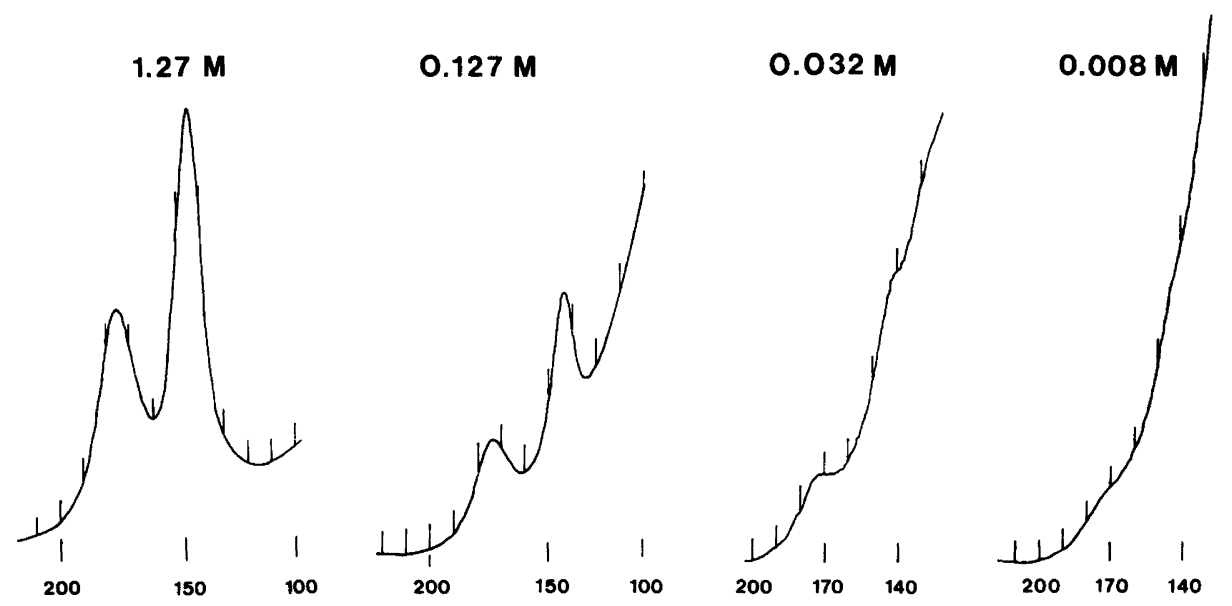

Fig. 1. The Raman spectra of $\mathrm{HgIClO}_{4}$ solution in DMSO.

$\mathrm{cm}^{-1}$ and $175 \mathrm{~cm}^{-1}$, are present for the saturated solution. These have previously been assigned to the symmetric stretching frequencies of the $\mathrm{HgI}_{2}$ and $\mathrm{Hg}_{2} \mathrm{I}^{3+}$ complexes, respectively. ${ }^{4}$ In this saturated solution, with equimolar amounts of $\mathrm{HgI}_{2}$ and $\mathrm{Hg}_{2} \mathrm{I}^{3+}$, the peak due to $\mathrm{HgI}_{2}$ is considerably more intense than that due to $\mathrm{Hg}_{2} \mathrm{I}^{3+}$. The same two peaks are present in the spectrum of the $0.127 \mathrm{M}$ solution. The intensities of the peaks are now similar, as a comparison with Fig. 1 in Ref. 3 also shows. This means that the disproportionation of $\mathrm{HgI}^{+}$is far from complete in a $0.127 \mathrm{M}$ solution. The contribution to the high-frequency peak from $\mathrm{HgI}^{+}$is negligible in DMSO solutions of $\mathrm{HgIClO}_{4}$ more concentrated than $0.35 \mathrm{M}$. For the two dilute solutions, the high-frequency peak is the most pronounced one and is shifted slightly to $173 \mathrm{~cm}^{-1}$.

Potentiometric measurements of dilute DMSO solutions show a complex distribution of $80 \% \mathrm{HgI}^{+}$and $10 \%$ each of $\mathrm{Hg}^{2+}$ and $\mathrm{HgI}_{2}$ in a $\mathrm{HgIClO}_{4}$ solution. ${ }^{1}$ There is no indication of polynuclear species in dilute solutions. Although these measurements require an ionic media, there is no reason to expect any major changes in the complex distribution in the studied solutions. The peak at $173 \mathrm{~cm}^{-1}$ can therefore be assigned to the $\mathrm{HgI}^{+}$complex. The structure of the DMSO-solvated $\mathrm{HgI}^{+}$complex determined by EXAFS is shown in Fig. 2.

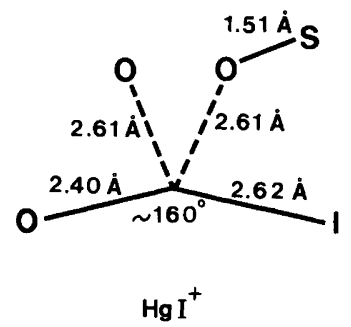

Fig. 2. The structure of the DMSO solvated HgI+ complex.

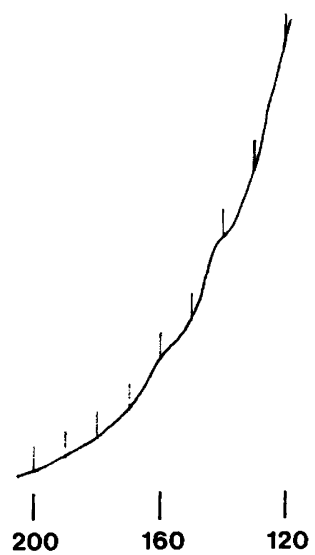

Fig. 3. The Raman spectrum of the saturated $\mathrm{HgIClO}_{4}$ solution in pyridine.

Acta Chem. Scand. A 39 (1985) No. 7 
Table 1. The $\mathrm{Hg}-\mathrm{X}$ stretching frequencies, in $\mathrm{cm}^{-1}$, of the $\mathrm{HgX}^{+}$and $\mathrm{HgX}_{2}$ complexes in aqueous, DMSO and pyridine solution at ambient temperature.

\begin{tabular}{lccc}
\hline Complex & Water & DMSO & Pyridine \\
\hline $\mathrm{HgI}^{+}$ & $191^{a}$ & $173^{c}$ & $159^{c}$ \\
$\mathrm{HgBr}^{+}$ & $234^{a}$ & - & - \\
$\mathrm{HgCl}^{+}$ & $338^{a}$ & - & - \\
$\mathrm{HgI}_{2}{ }^{b}$ & 151 & 145 & 142 \\
$\mathrm{HgBr}_{2}{ }^{b}$ & 205 & 195 & 183 \\
$\mathrm{HgCl}_{2}{ }^{b}$ & 320 & 303 & 283 \\
\hline
\end{tabular}

${ }^{a}$ Ref. 8. ${ }^{b}$ Ref. $11 .^{c}$ This work.

The Raman spectrum of a saturated solution $(\sim 25 \mathrm{mM})$ of $\mathrm{HgIClO}_{4}$ in pyridine shows two very weak bands at $142 \mathrm{~cm}^{-1}$ and $159 \mathrm{~cm}^{-1}$ on the wing of the strong Rayleigh line, Fig. 3 . These bands are assigned to $\mathrm{Hg}-\mathrm{I}$ stretching vibrations in the pyridine solvated $\mathrm{HgI}_{2}{ }^{10}$ and $\mathrm{HgI}^{+}$complexes, respectively. The solution studied in this work is only slightly more concentrated than those used in the potentiometric study. ${ }^{2}$ At the stoichiometric composition $\mathrm{HgIClO}_{4}$, the equilibrium constants give a complex distribution of $82 \% \mathrm{HgI}^{+}$ and $9 \%$ each of the $\mathrm{Hg}^{2+}$ and $\mathrm{HgI}_{2}$ species with no indications of polynuclearity. This seems sufficient to account for the observation of the very intense $\mathrm{Hg}-\mathrm{I}$ band of the $\mathrm{HgI}_{2}$ species in comparison to the much weaker $\mathrm{Hg}-\mathrm{I}$ band of $\mathrm{HgI}^{+}$.

No bands from the $\mathrm{HgBr}^{+}$or $\mathrm{HgCl}^{+}$complexes, which probably have low Raman intensities, could be detected in the dilute pyridine solutions nor in the concentrated DMSO solutions due to overlap with other bands.

The coordination of a solvent molecule trans to the iodide in the $\mathrm{HgI}^{+}$ion affects the $\mathrm{Hg}$-I vibrational frequency. The softer the donor atom, $\mathrm{L}$, of the solvent molecule, the greater the expected shift in frequency, see Table 1 . A similar but much less pronounced effect is observed for the $\mathrm{HgX}_{2}$ molecules. This supports the EXAFS results that the trans ligand in the $\mathrm{HgX}^{+}$ion is the most strongly bonded, and that further solvation is weaker and has only a secondary influence on the $\mathrm{L}-\mathrm{Hg}-\mathrm{X}$ entity for solvents with donor atoms $\mathrm{L}$ less soft than the $\mathrm{X}$ ligand.

Acknowledgement. The financial support of The Swedish Natural Science Research Council is gratefully acknowledged.

1. Ahrland, S., Persson, I. and Portanova, R. Acta Chem. Scand. A 35 (1981) 49.

2. Ahrland, S., Ishiguro, S.-I., Marton, A. and Persson, I. Acta Chem. Scand. A 39 (1985) 227.

3. Ahrland, S., Hansson, E., Iverfeldt, Å. and Persson, I. Acta Chem. Scand. A 35 (1981) 275.

4. Sandström, M. Acta Chem. Scand. A 32 (1978) 627.

5. Penner-Hahn, J.E. and Persson, I. To be published.

6. Persson, I., Sandström, M., Goggin, P.L. and Mosset, A. J. Chem. Soc. Dalton Trans. In press.

7. Bengtsson, L., Holmberg, B., Iverfeldt, Å. and Persson, I. To be published.

8. Clarke, J.H.R. and Woodward, L.A. Trans. Faraday Soc. 61 (1965) 207.

9. Sandström, M., Persson, I. and Ahrland, S. Acta Chem. Scand. A 32 (1978) 607.

10. Smith, J.H. and Brill, T.B. Inorg. Chim. Acta 18 (1976) 225.

11. Persson, I., Sandström, M. and Goggin, P.L. To be published.

Received March 25, 1985. 